University of Montana

ScholarWorks at University of Montana

Graduate Student Theses, Dissertations, \&

Professional Papers

1997

\title{
Emotional awareness and couples' relationship satisfaction
}

Kristin L. Croyle

The University of Montana

Follow this and additional works at: https://scholarworks.umt.edu/etd

Let us know how access to this document benefits you.

\section{Recommended Citation}

Croyle, Kristin L., "Emotional awareness and couples' relationship satisfaction" (1997). Graduate Student Theses, Dissertations, \& Professional Papers. 5304.

https://scholarworks.umt.edu/etd/5304

This Thesis is brought to you for free and open access by the Graduate School at ScholarWorks at University of Montana. It has been accepted for inclusion in Graduate Student Theses, Dissertations, \& Professional Papers by an authorized administrator of ScholarWorks at University of Montana. For more information, please contact

scholarworks@mso.umt.edu. 


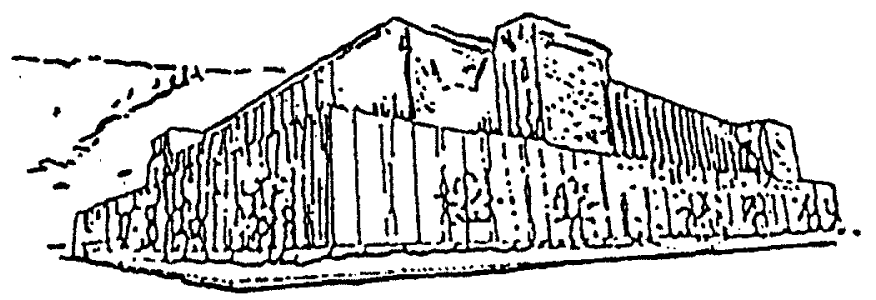

\section{Maureen and Mike MANSFIELD LIBRARY}

\section{The University of $\mathbb{M O N T \mathbb { N A }}$}

Permission is granted by the author to reproduce this material in its entirety, provided that this material is used for scholarly purposes and is properly cited in published works and reports.

** Please check "Yes" or "No" and provide signature **

Yes, I grant permission

No, I do not grant permission

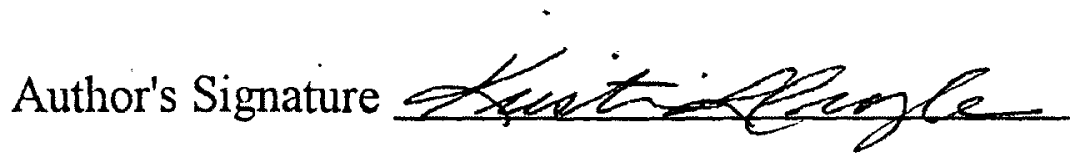

Date February 26, 1997

Any copying for commercial purposes or financial gain may be undertaken only with the author's explicit consent. 


\section{EMOTIONAL AWARENESS AND}

COUPLES' RELATIONSHIP SATISFACTION

by

Kristin L. Croyle

B. S., University of Utah, 1994

Presented in partial fulfillment of the

requirements for the degree of

Master of Arts

THE UNIVERSITY OF MONTANA

1997

Approved by:

Qunniee Walt, PhD Chair, Master's Thesis Committee

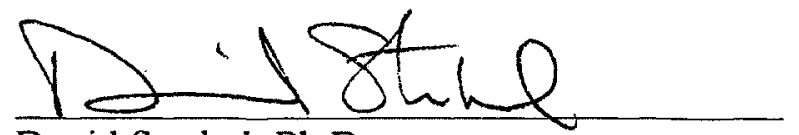

David Strobel, Ph.D.

Dean, Graduate School

$\overline{\text { Date }}$

$3-5-97$ 


\section{All rights reserved}

\section{INFORMATION TO ALL USERS}

The quality of this reproduction is dependent upon the quality of the copy submitted.

In the unlikely event that the author did not send a complete manuscript and there are missing pages, these will be noted. Also, if material had to be removed, a note will indicate the deletion.

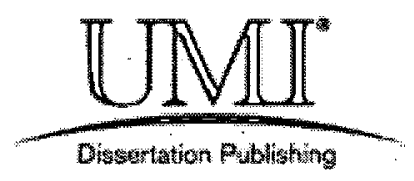

UMI EP40768

Published by ProQuest LLC (2014). Copyright in the Dissertation held by the Author.

Microform Edition @ ProQuest LLC.

All rights reserved. This work is protected against unauthorized copying under Title 17, United States Code

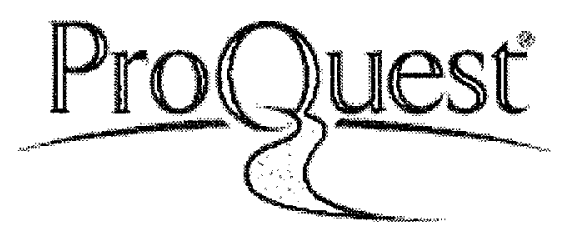

ProQuest LLC.

789 East Eisenhower Parkway

P.O. Box 1346

Ann Arbor, MI 48106 - 1346 
Author: Croyle, Kristin L., B.S., 1994

Title: Emotional Awareness and Couples' Relationship Satisfaction

Director: Jennifer Waltz, Ph.D.

Recent models of couples relationship satisfaction and couples therapy emphasize the importance of emotional awareness (Greenberg \& Johnson, 1986; Jacobson \& Christensen, 1996). Emotional awareness is the realization that one is experiencing an emotion. This experiencing can occur at several different levels, from physiological arousal to cognitive reflection. This study examined the role of emotional awareness in couples' relationships. Additionally, the effects of a tendency to respond to difficult couples situations with "soft" emotions (including sadness and fear) versus "hard" emotions (including anger and resentment) on the couple relationship were examined.

Participants were 56 heterosexual couples who completed a measure of relationship satisfaction, and two measures of emotional awareness, including one that was developed as part of this study. Results indicate that women are more emotionally aware than men in response to couples situations, but not in response to general situations. Additionally, higher levels of emotional awareness and a higher awareness of "hard" emotions are associated with decreased relationship satisfaction for women, but not for men. Discrepancy between partners' levels of awareness is related to lower satisfaction for both men and women. The direction of this discrepancy is not important for men, but for women, as their partner's emotional awareness decreases, women's relationship satisfaction tends to also decrease. Emotional awareness appears to be a significant factor in couples relationships, although its association with relationship satisfaction is complex and requires further research.

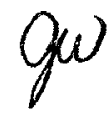


Table of Contents

Title Page $\ldots \ldots \ldots \ldots \ldots \ldots \ldots \ldots \ldots \ldots \ldots \ldots \ldots \ldots \ldots$

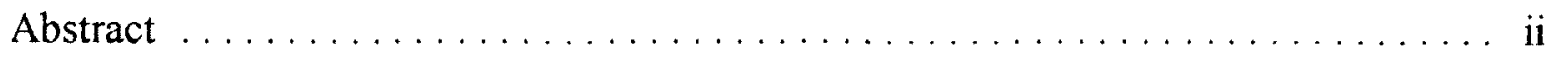

Table of Contents $\ldots \ldots \ldots \ldots \ldots \ldots \ldots \ldots \ldots \ldots \ldots \ldots \ldots \ldots \ldots$ iii

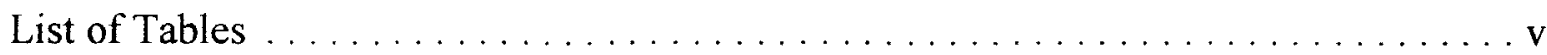

Introduction and Literature Review $\ldots \ldots \ldots \ldots \ldots \ldots \ldots \ldots \ldots \ldots$

Emotional Awareness and Emotional Experiencing $\ldots \ldots \ldots \ldots \ldots \ldots$

Emotional Awareness and Couples' Relationships . . . . . . . . . . . . . 9

Assessing Emotional Awareness $\ldots \ldots \ldots \ldots \ldots \ldots \ldots \ldots \ldots \ldots$

The Levels of Emotional Awareness Model and Scale . . . . . . . . . . 17

The Couples' Emotional Awareness Scale . . . . . . . . . . . . . . . . 22

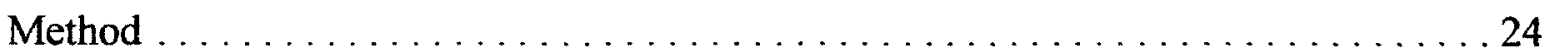

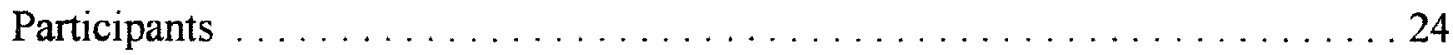

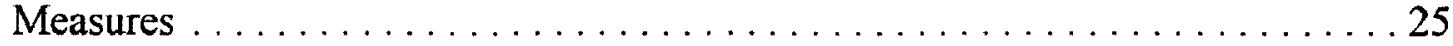

Dyadic Adjustment Scale . . . . . . . . . . . . . . . . . 25

Levels of Emotional Awareness Scale . . . . . . . . . . . . . . 27

Couples' Emotional Awareness Scale . . . . . . . . . . . . . . . . . . . . . 29

Vocabulary section of the Wechsler Adult Intelligence Scale - Revised . . 30

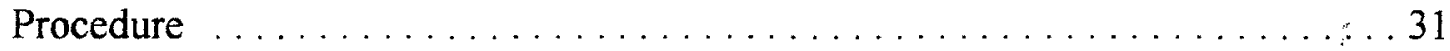

Results .................................. 31

CEAS Reliability and Validity $\ldots \ldots \ldots \ldots \ldots \ldots \ldots \ldots \ldots \ldots \ldots \ldots \ldots \ldots \ldots \ldots \ldots \ldots$

Relationship Between Emotional Awareness and Relationship Satisfaction . . . . 32

Predicting Relationship Satisfaction from Emotional Awareness . . . . . . . . . 34

Relationship Between Discrepancy Scores and Relationship Satisfaction . . . . 38

Effect of Gender on Level of Emotional Awareness . . . . . . . . . . . 40

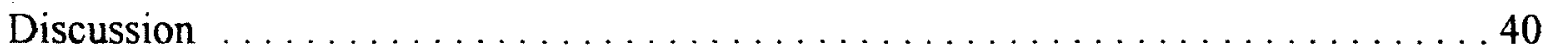

Gender Differences in Emotional Awareness . . . . . . . . . . . . . . 40

The Association between Discrepancy in Partners Levels of Emotional

Awareness and Relationship Satisfaction ... . . . . . . . . . 45

The Association between Emotional Awareness and Relationship Satisfaction . 47

Level of Emotional Awareness . . . . . . . . . . . . . . . . 47

Hard and Soft Emotions . . . . . . . . . . . . . . . . 50

Implications for Therapy and Research $\ldots \ldots \ldots \ldots \ldots \ldots \ldots \ldots \ldots \ldots \ldots \ldots \ldots$ 


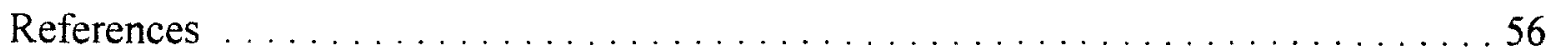

Appendices . . . . . . . . . . . . . . . . . . . . . . . . . . 59

Appendix A: Levels of Emotional Awareness Scale . . . . . . . . . . . . 59

Appendix B: Couples' Emotional Awareness Scale . . . . . . . . . . . 62

Appendix C: Dyadic Adjustment Scale . . . . . . . . . . . . . . . 64

Appendix D: Couples' Emotional Awareness Scale, Scoring Instructions for Hard and Soft Emotions . . . . . . . . . . . . . . . . . 68 
List of Tables

Table 1 Five Levels of Structural Transformation of Knowledge About the External World and the Internal World . . . . . . . . . . . . . . . . . . 20

Table 2 Characteristics of Five Levels of Emotional Awareness . . . . . . . . . 21

Table 3 Demographic Characteristics of Participating Couples . . . . . . . . . 26

Table 4 Correlations of Emotional Awareness Scales and Dyadic Adjustment Scale ................................. 33

Table 5 Hierarchical Multiple Regression: Predicting Relationship Satisfaction from Personal Emotional Awareness Scores . . . . . . . . . . . . . . . 36

Table 6 Hierarchical Multiple Regression: Predicting Relationship Satisfaction from Partner Emotional Awareness Scores . . . . . . . . . . . . . . . . . . . 37

Table 7 Correlations Between Discrepancy in Emotional Awareness and Relationship Satisfaction . 39 
Introduction and Literature Review

Recent models of couple relationship satisfaction and couples therapy emphasize the importance of emotions and, in particular, emotional awareness (Greenberg \& Johnson, 1986; Jacobson \& Christensen, 1996). These models generally suggest that being able to access and be aware of the presence of a range of emotions is helpful in maintaining satisfaction in couples relationships. It may be that couples need to be able to understand what they are feeling in order to engage in other important relationship behaviors, such as expressing feelings, enhancing intimacy, and problem solving; however, these recent models of couple satisfaction suggest somewhat different ways that emotional awareness is important in couples relationships. Greenberg and Johnson (1986) suggest that greater emotional awareness is, in general, conducive to more satisfying relationships. Jacobson and Christensen (1996), on the other hand, suggest that awareness and expression of "soft" emotions, such as sadness and fear, as opposed to "hard" emotions, such as anger and resentment, are critical to couple satisfaction. The purpose of this study is to examine the role of emotional awareness in couples and its relationship to couples satisfaction. This study will look at the roles of both general emotional awareness and awareness of "soft" versus "hard" emotions within the context of the couple relationship. Understanding the role of emotional awareness in couples relationships will increase our understanding of the processes within these relationships that are related to having a satisfying couple relationship, and will inform approaches to couple therapy. 


\section{Emotional Awareness and Emotional Experiencing}

Emotional awareness is an important construct in almost every significant psychotherapeutic theory. The term "emotional awareness" is generally used to describe the realization that one is experiencing emotion. This awareness can occur at several levels; it can include realizing that one is physiologically aroused, that this arousal has action tendencies associated with it such as an urge to run away or fight, and that these sensations have global qualities such as feeling "bad" or "good." Awareness can also extend to the emotion being experienced as distinct in some ways from other emotions, with the person thus being able to attach a specific label to it such as "happy" or "excited." Increasing awareness also includes realizing that several of these emotions are occurring simultaneously, such as feeling "excited" and "scared" at the same time. Emotional awareness can also include interpersonal aspects, such as the realization that others are feeling emotions and that those emotions are distinct from the emotions experienced by the self.

Emotional experiencing, on the other hand, is generally considered to be synonymous with feeling, which can be viewed as having or perceiving a physical sensation or a state of mind. Experiencing is also often used to describe the act of allowing an experience to be felt with little concurrent reflection on what may be happening. In contrast, awareness generally involves knowing or realizing that something exists. In other words, awareness includes experiencing, because being aware that an emotion exists obviously requires 
experiencing that emotion, but it also includes cognitive reflection on what is being experienced.

The importance of emotional awareness to psychological health has been emphasized as an important variable in many significant psychotherapeutic theories. A lack of emotional awareness is seen by many schools of therapy as responsible, or partially responsible, for different types of psychopathology or human suffering. These models tend to view a lack of emotional awareness, or having important emotional responses that are either out of awareness or blocked in some way, as a cause of various psychological problems. These theories typically make the assumption that in order to "process" painful emotions successfully, people need to first allow themselves to experience, and be aware of those emotions. In early psychoanalytic theory, Freud emphasized the counterpart of emotional awareness, the suppression of affect, in creating and maintaining neurotic symptoms (see Greenberg \& Safran, 1987). In contemporary ego analysis, Blanck and Blanck (1979) emphasize the importance of the "corrective emotional experience," which involves fully experiencing affective responses within the context of the therapeutic relationship. This process is conceptualized as the primary mechanism of change which results in the patient's distortions of the object world being corrected. In experiential therapies, affect is generally seen as a system that provides feedback to the individual and helps him or her to adapt to the environment. Because of its adaptive function, awareness of emotions is critical (Raskin \& Rogers, 1989). 


\section{Emotional Awareness and Couples' Relationships}

Several current theories of couples functioning view emotional awareness as critical to having a satisfying relationship. For example, Greenberg and Johnson's (1988) Emotionally Focused Therapy for Couples (EFT) is designed to help couples identify unexpressed, underlying emotions and to redefine the couple's interactions in terms of these newly experienced emotions. In other words, they attempt to enhance emotional awareness and then help the couple to make use of their newly enriched awareness. This model is based on the assumption that unhappy couples are not aware of important emotions, and that this lack of awareness leads to relationship distress.

In a test of their model, Johnson and Greenberg (1988) found that couples that showed higher levels of emotional experiencing in therapy were indeed generally more successful and ended therapy more satisfied than couples who showed lower experiencing. Higher experiencing was defined as receiving higher scores on the Experiencing Scale (Klein, Mathieu-Coughlan, \& Keisler, 1969; as cited in Johnson \& Greenberg, 1988), which measures client involvement in therapy, from superficial involvement at low levels to exploration of new feelings and development of greater self-understanding at high levels. The experiencing described by Klein and her colleagues is very similar to our concept of awareness, in that exploration of new feelings requires cognitive reflection, or awareness, in order for it to occur. The tie between greater awareness or expression and greater satisfaction has been replicated at least three times in the context of process research on EFT (see Jacobson \& Addis, 1993, for discussion), including one therapeutic application that 
included an added communication training component (James, 1991). These findings support the notion that reaching higher levels of emotional awareness improves relationship satisfaction.

Jacobson and Christensen (1996; Christensen, Jacobson, \& Babcock, 1995) have also proposed an association between emotional awareness and relationship satisfaction; however they focus more on the awareness of specific emotions rather than on enriching general emotional awareness. Dissatisfied couples tend to express more overt anger, criticism, disgust, etc., than satisfied couples (Gottman \& Levenson, 1988). Jacobson and Christensen label these as "hard" emotions, which include these feelings as well as cognitions related to power and control. Hard emotions tend to place the self in a stronger, more dominant position vis a vis the partner. Jacobson and Christensen propose that almost every hard feeling has a "soft" feeling or thought associated with it. Soft feelings include hurt, fear, sadness, and disappointment and involve cognitions around doubt, uncertainty, and danger. These feelings reveal the self as vulnerable relative to the partner. Hard feelings, for example anger and resentment, may have soft feelings associated with them, such as hurt and disappointment. According to this model, if a couple can express soft feelings with each other, as well as hard feelings, they will be able to develop greater empathy and acceptance of each other, communicate more effectively, and experience more intimacy. Jacobson and Christensen have incorporated this distinction between hard and soft emotions into their Integrative Couple Therapy approach. Tests of this model are currently underway.

Consider the following illustration of how emotional awareness may affect a couple's 
interaction. Kelly spends a lot of time out with her friends and her partner, Tom, becomes angry as a result. This situation could have several different outcomes depending on Tom's emotional awareness (as well as other variables). If Tom is unaware that he is angry at all, he may experience physical sensations of anger including increased muscle tension, heart rate, and energy and may often seem irritable. He would be likely to respond to the situation by acting angry, criticizing, being cold and distant, or complaining. However, he would be less likely to be able to talk about his feelings or to make connections between his anger and Kelly's behavior. Not being able to talk about his feelings would make problem-solving less likely to occur.

If Tom is aware that he is angry, he might be more likely to be able to talk to Kelly about his feelings, rather than criticize. He might say "It makes me angry when you don't put effort into spending time with me." This may communicate his anger to her and allow them an opportunity to work on the situation. However, Kelly may also become defensive as a result and be less likely to problem solve.

If Tom, in addition to his anger, is also experiencing underlying feelings of hurt or fear, and he becomes aware of these, he would be more likely to express them. He may respond by saying "You're always out with your friends. I'm hurt because I feel like you don't enjoy being with me and I'm afraid that you're going to leave me." This response would communicate his range of feelings and may be more likely to elicit an empathic and caring response from Kelly. If Kelly sees that her behavior is painful to Tom, and he allows himself to be vulnerable with her, she may be less inclined to defend herself. 
Greenberg and Johnson's model and Jacobson and Christensen's model would have similar predictions about the effect of Tom's emotional awareness on the couple's relationship. Both models would agree that Tom's three possible responses reflect a progressively increasing level of emotional awareness, and could facilitate an increasing level of relationship satisfaction. However, consider a situation in which awareness and expression of hard versus soft emotions is at issue, such as if Tom was aware of anger but was also experiencing underlying sadness. In this situation, these two models would have slightly different emphases. Greenberg and Johnson would focus more on increasing general emotional awareness, without making a strong distinction between the specific emotions in question. Jacobson and Christensen, although supporting increases in general emotional awareness, would focus more on increasing awareness of soft emotions, because most dissatisfied couples already express a great deal of hard emotions, such as anger.

Research on couples satisfaction that has looked primarily at emotional expression provides some support for the hypothesis that emotional awareness plays an important role in couples relationships. Emotional awareness may be a necessary prerequisite to certain types of emotional expression, in particular to describing one's own emotional responses and reactions. All major theories of emotion that include a cognitive component to emotional experience and which emphasize cognitions as consciously experienced (Arnold, 1960; Lazarus, 1982; Mandler, 1984; Schachter \& Singer, 1962; etc.) are in effect proposing that emotional awareness, at a cognitive level, must precede or at least co-occur with emotional expression. 
If emotional awareness facilitates emotional expression, then greater awareness may prevent emotional withdrawal, thus increasing relationship satisfaction. For example, several researchers have found ties between emotional withdrawal and low couples satisfaction. Husbands in low satisfaction relationships withdraw more than satisfied husbands (Gottman \& Levenson, 1988), withdrawal predicts low satisfaction longitudinally (Gottman \& Krokoff, 1989), and withdrawal from conflict predicts long-term relationship distress (Holtzworth-Munroe \& Jacobson, 1991). It may be that individuals with low levels of emotional awareness are less able to describe their emotional responses, so they tend to withdraw more from interactions where describing those responses plays a major role, such as in conflict or indeed in many situations in intimate relationships. It may also be that couples in dissatisfying relationships experience more difficult emotions in their relationships, and that these emotions are particularly difficult to cope with, so the individual withdraws from the interaction to avoid experiencing these emotions. However, by not dealing directly with the source of these feelings, the couple may eventually become more and more distressed, as Holtzworth-Munroe's \& Jacobson's findings illustrate (1991). It is possible that more satisfied couples are more aware of their emotions, and thus can more easily discuss and resolve difficult emotions within the relationship, whereas less emotionally aware couples may be less able to productively problem solve regarding their difficult emotions because they are less aware that they are experiencing them.

Even if emotional expression were possible without prior or concurrent emotional awareness, it may be counterproductive to function exclusively in this way within a 
relationship. Experiencing emotion without awareness of it would make it more difficult to discuss it productively with your partner, as illustrated by the first response of the male partner in the above scenario. This is supported by robust findings regarding communication skills. Satisfied couples show better communication skills than unsatisfied couples (Holtzworth-Munroe \& Jacobson, 1991). Communication skill level also predicts later satisfaction with the relationship (Holtzworth-Munroe \& Jacobson, 1991). An important aspect of effective communication is discussing significant areas of the relationship. It would seem that even the couple with the best possible communication skills would be doomed if their skills did not include being able to talk about feelings, which requires emotional awareness.

In addition to generally facilitating emotional expression, emotional awareness may facilitate expression of a broader range of emotions. Most complex human situations can spur a variety of often conflicting emotional responses. A low level of emotional awareness may enable perception of only the predominant or most immediately powerful response (such as anger in the above situation). Greater emotional awareness allows for recognition of other affective responses (such as sadness or fear in the above situation), making available a broader range of emotions to express, and a broader set of coping responses to use that are associated with the new emotions expressed.

This is one of the purposes of focusing on emotional awareness in psychotherapy; assisting a client to develop greater emotional awareness may help the client to develop new emotional responses to a difficult situation. For example, consider a client that responds 
depressively to any situation involving criticism, thinking "They're right. I'm a failure, a terrible person, and I can't do anything right." This client could be helped to develop new awareness and expression of other feelings, such as anger ("This person is always criticizing me for no good reason. This makes me angry!"), or hopefulness ("This is a great opportunity to get some constructive feedback so that I can improve in this area."). As a result, they could work on different coping responses, such as assertiveness in response to the anger ("I think you aren't looking at my work objectively and I think your criticisms are unfair."), or openness to change in response to viewing the situation as an opportunity for improvement ("Thank you for your feedback. You've made some good points that I'll try to work on."). This focus on expanding awareness to foster a broader range of emotional responses is emphasized in Greenberg and Johnson's Emotionally Focused Therapy for couples. Indeed, Greenberg and Johnson (1988) found that when couples were assisted in expressing underlying feelings (which the individuals were not initially aware of), the couples reported changes in interpersonal perception and greater expression of feelings and needs. In other words, when emotional awareness was increased in therapy, emotional expression increased as a result. These results support the argument that emotional awareness is related to emotional expression.

The predominance of negative affect in dissatisfied relationships also supports this hypothesis and clarifies its relationship to couple satisfaction. For example, Gottman and Levenson (1988) found that unsatisfied wives tend to argue about insignificant aspects of their relationships more than satisfied wives and that unsatisfied couples show more 
negative affect, including anger, fear, disgust, etc. If emotional awareness facilitates expression of a broader range of emotions, then greater awareness may add a wider range of emotional responses to the repertoires of these couples. This may also affect the withdrawal patterns discussed above in a similar way, in that having a wider range of emotional responses to express may combat emotional withdrawal by providing other alternatives to withdrawal.

The correlational nature of this research does not rule out the possibility that couples who are less satisfied and are aware of more negative affect in their relationships may experience emotional awareness as aversive and may lower their level of emotional awareness in response. However, Johnson and Greenberg's findings (1988), that couples who showed more experiencing in therapy became more satisfied than couples who showed lower experiencing suggest that the direction of causality is that emotional awareness affects relationship satisfaction rather than the reverse.

The interaction between the levels of emotional awareness of each partner in a couple may also have important implications for their relationship. Partners may have similar or highly discrepant levels of emotional awareness. If the partners are discrepant in their levels of awareness, their attempts at communicating their feelings to each other may not be understood by the other partner, contributing to a general dissatisfaction. For example, consider a relationship in which when the male partner feels intimate and cared about, he verbally states "I feel cared about and close to you," while when his female partner feels intimate and cared about, she initiates sex. In this situation, the man may feel that his 
partner is never feeling close to him, but does enjoy sex quite a bit. His partner, on the other hand, may feel that he rarely really feels close to her because he does not initiate sex often. Mitchell's findings (1988) support the importance of a discrepancy in level of emotional awareness in a relationship. She found that distressed marriages often include partners who have difficulty communicating feelings, although one partner is often substantially more verbal than the other. This could be interpreted to mean that greater emotional awareness may be generally helpful for the couple to aid them in communicating feelings (as discussed above), but this may not be as helpful if one partner is substantially more adept at communicating feelings than the other.

Thus, emotional awareness may have an important impact on relationship satisfaction, as supported by the theories of Greenberg and Johnson (1986) and Jacobson and Christensen (1996). This impact may occur through several mechanisms. Greater levels of awareness may encourage clearer emotional expression by encouraging talking about feelings rather than simply acting them out. Additionally, greater levels of awareness may encourage expression of a broader range of emotions. Each of these could in turn encourage more effective communication and problem solving, and discourage withdrawal, which would increase relationship satisfaction. However, if the levels of awareness are very discrepant between partners, awareness may actually contribute to dissatisfaction in that their efforts to communicate their feelings to each other may not be easily understood.

\section{Assessing Emotional Awareness}

The Levels of Emotional Awareness Model and Scale. Lane and Schwartz (1987) have 
proposed a cognitive-developmental model of emotional awareness. The primary thesis of this model is that "emotional awareness is a type of cognitive processing which undergoes five levels of structural transformation along a cognitive-developmental sequence derived from an integration of the theories of Piaget and Werner" (Lane and Schwartz, 1987, p. 134). Lane and Schwartz hold that emotional responses are preceded by cognitive appraisals of the environment and then subjected to a series of subsequent cognitive processes that form what is experienced as emotion.

The developmental aspects of this cognitive-developmental model stem from the contributions of Werner and Piaget. Werner (1957) proposed that symbolic processes determine the nature of experience. Through symbolizing features of experience in a schematizing activity, a person can make explicit aspects of experience that would otherwise remain fluid and inaccessible. He further proposed that this symbolic activity proceeds developmentally from a state of relative globality and lack of differentiation to a state of increasing differentiation, articulation, and structure. This is true both in general cognitive development (orthogenesis) and in the development of cognitive activity at any given moment (microgenesis). Lane and Schwartz (1987) applied Werner's ideas by proposing that emotional development proceeds in the same way as cognitive development, following both ontogenetic and microgenetic principles of increasing differentiation, articulation, and structure.

If emotional development does indeed follow the same pattern as cognitive development, as Lane and Schwartz suggest, then emotional development may follow the sequence 
described by Piaget for cognitive development. Piaget's theory of cognitive development proposes four stages in which there is an increasing trend toward abstraction and coordination of schemata (Flavell, 1963). Lane and Schwartz (1987) divide emotional development into five levels corresponding to Piaget's four stages (splitting the first stage into two). Table 1 (page 20) lists Piaget's stages and links the corresponding structural transformations of knowledge about the external world to the structural transformations of knowledge about the internal world. Table 2 (page 21) lists the characteristics of Lane and Schwartz' five levels of emotional awareness. Generally each level in both tables represents a hierarchical increase in differentiation and integration from the previous level. Lane and Schwartz used the term "level" to indicate that it could apply to momentary states or to an individual's usual level of functioning.

Lane, Quinlan, Schwartz, Walker, and Zeitlin (1990) operationalized Lane and Schwartz' original model in the Levels of Emotional Awareness Scale (LEAS; see Appendix A, page 59) in a manner designed to identify the five levels of emotional awareness. The LEAS presents brief interpersonal situations and then asks how the individual would feel and how the other person in the situation would feel.

The LEAS provides a useful way to conceptualize emotional awareness, and is better suited to this application than other existing measures. It provides a usable method of investigating individual differences in the experience and expression of emotion outside of a therapy session. There are two other useful techniques for assessing individual differences in experiencing, the Experiencing Scale (Klein, Mathieu, Gendlin, and Kiesler, 1969; as 
Table 1

Five Levels of Structural Transformation of Knowledge About the External World and the Internal World

\begin{tabular}{lll}
\hline Level of Structural & External World & Internal World
\end{tabular}

Transformation

Formal Operational Able to reason abstractly using

hypotheticodeductive reasoning; able to consider all possibilities in a situation

\section{Concrete}

Operational

Preoperational

\section{Sensorimotor}

(substages 2-6)

Sensorimotor (substage 1)
Several attributes of an object integrated into unified concepts (e.g., conservation of volume), but reasoning based on immediate experience

Has concept of individual attributes of objects that may be used idiosyncratically to represent the object as a whole

Learns about objects through handling and perceiving them

Has reflexive (involuntary motor) responses at interface with external world (e.g., sucking)
Able to experience many nuances of emotion; own experience does not limit empathic awareness of other's experience

Multifaceted emotional experience includes experiencing opposite feelings and blends of emotion as part of a single reaction

Has unidimensional, pervasive emotional reactions; emotional experience has an either/or quality

Able to induce a change in undifferentiated emotional state through actions on the environment

Has reflexive (involuntary motor) responses, both internally (autonomic, neuroendocrine) and at interface with environment (e.g., facial expression)

Note. From "Levels of Emotional Awareness: A Cognitive-Developmental Theory and its Application to Psychopathology," by R. D. Lane and G. E. Schwartz, 1987, American Journal of Psychiatry, 144(2), p. 137. 
Table 2

Characteristics of Five Levels of Emotional Awareness

\begin{tabular}{|c|c|c|c|c|}
\hline $\begin{array}{l}\text { Level of Emotional } \\
\text { Awareness }\end{array}$ & $\begin{array}{l}\text { Subjective Quality of } \\
\text { Emotional Experience }\end{array}$ & $\begin{array}{l}\text { Differentiation of } \\
\text { Emotion }\end{array}$ & $\begin{array}{l}\text { Ability to Describe } \\
\text { Emotion }\end{array}$ & Empathy \\
\hline $\begin{array}{l}\text { Formal } \\
\text { Operational }\end{array}$ & $\begin{array}{l}\text { Peak differentiation } \\
\text { and blending }\end{array}$ & $\begin{array}{l}\text { Richer differen- } \\
\text { tiations of quality and } \\
\text { intensity }\end{array}$ & $\begin{array}{l}\text { Description of more } \\
\text { complex and } \\
\text { differentiated states }\end{array}$ & $\begin{array}{l}\text { Multifaceted awareness of } \\
\text { other's state based on ability to } \\
\text { imagine self in other's context }\end{array}$ \\
\hline $\begin{array}{l}\text { Concrete } \\
\text { Operational }\end{array}$ & $\begin{array}{l}\text { Differentiated, } \\
\text { attenuated emotion }\end{array}$ & $\begin{array}{l}\text { Blends of emotion, } \\
\text { concurrence of } \\
\text { opposing emotions }\end{array}$ & $\begin{array}{l}\text { Description of } \\
\text { differentiated emotions }\end{array}$ & $\begin{array}{l}\text { Attribution of experience } \\
\text { based only on own percep- } \\
\text { tions and own experience }\end{array}$ \\
\hline Preoperational & Pervasive emotion & $\begin{array}{l}\text { Either/or experience } \\
\text { of emotional extrem- } \\
\text { es (limited repertoire) }\end{array}$ & $\begin{array}{l}\text { Description of uni- } \\
\text { dimensional emotion }\end{array}$ & $\begin{array}{l}\text { Idiosyncratic or inconsistent } \\
\text { awareness of other's } \\
\text { experience }\end{array}$ \\
\hline $\begin{array}{l}\text { Sensorimotor } \\
\text { Enactive }\end{array}$ & $\begin{array}{l}\text { Action tendency } \\
\text { and/or global arousal }\end{array}$ & $\begin{array}{l}\text { Action tendency or } \\
\text { global hedonic state }\end{array}$ & $\begin{array}{l}\text { Description of action } \\
\text { tendencies or global } \\
\text { hedonic states }\end{array}$ & $\begin{array}{l}\text { Motor mimicry, identification } \\
\text { through behavior }\end{array}$ \\
\hline $\begin{array}{l}\text { Sensorimotor } \\
\text { Reflexive }\end{array}$ & Bodily sensation & $\begin{array}{l}\text { Global undifferen- } \\
\text { tiation of arousal }\end{array}$ & $\begin{array}{l}\text { No description or } \\
\text { description of bodily } \\
\text { sensation }\end{array}$ & $\begin{array}{l}\text { Reflexive empathy (e.g., } \\
\text { crying when other cries) }\end{array}$ \\
\hline
\end{tabular}

Note: From "Levels of Emotional Awareness: A Cognitive-Developmental Theory and its Application to Psychopathology," by R. D. Lane and G. E. Schwartz, 1987, American Journal of Psychiatry, 144(2), p. 138-139. 
cited in Greenberg and Safran, 1987) and the Client Vocal Quality system (Rice, Koke, Greenberg, and Wagstaff, 1979; as cited in Greenberg and Safran, 1987); however, these measures rely on therapy sessions as the sole source of data so they are not appropriate for addressing many research questions outside the context of therapy. Although there are a few scales that attempt to measure individual differences in experiencing outside of therapy, none of them measures a developmental continuum, as the LEAS purports to (Lane, Quinlan, Schwartz, Walker, and Zeitlin, 1990).

Several specific hypotheses can be offered about the effect of emotional awareness, as measured by the LEAS, on relationship satisfaction. The theories of Greenberg and Johnson (1986) and Jacobson and Christensen (1996), propose that emotional awareness is associated with increases in relationship satisfaction. Thus, it can be hypothesized that a relationship will be found between couple satisfaction and scores on the LEAS. Mitchell's research (1988) supports the above hypothesis. This work also suggests that discrepancy between partners may be related to decreased satisfaction. A second question of interest, then, is whether overall level of awareness or discrepancy between partners is a better predictor of satisfaction.

The Couples' Emotional Awareness Scale. In addition to looking at the relationship between general level of emotional awareness and couple satisfaction, the current study focuses specifically on awareness of emotions that occur within the context of the couple relationship. It is likely that individuals may have different levels of emotional awareness in dealings with the world at large and in dealings specifically with their partners. For 
example, Gottman and Porterfield (1981; as cited in Gottman and Levenson, 1988) found that in satisfied couples men and women were equally able to understand ambiguous verbal messages delivered by their partners in a way to convey specific meaning (e.g., "I'm cold, aren't you?" in a way that conveyed either "I would like to snuggle" or "Please turn up the heat"). However in dissatisfied couples, men had a much more difficult time decoding the messages accurately, if they were delivered by their partners. These men were still able to decode these messages if delivered by someone other than their partner. These findings imply that awareness of others' emotions and emotional interaction in general is different between couples than it is in non-couple interactions. For this reason, the data yielded from the LEAS, with its general interactional scenarios, may not reflect a person's ability to be aware of emotions in the context of his or her relationship.

The current study also seeks to address the degree to which awareness of specific emotions, i. e. "hard" versus "soft," is related to couple satisfaction. Jacobson and Christensen (1996) propose that this distinction is particularly important to couple satisfaction. The LEAS does not allow for assessment of these types of emotions. It does not look at the specific emotions identified or the relationships between the emotions expressed. For example, the response "I would feel angry and resentful" would receive the same scoring as "I would feel angry and hurt" even though the second response reflects a wider range of emotional experience and includes both soft and hard emotions.

The current study includes development of a measure, the Couples' Emotional Awareness Scale (CEAS; see Appendix B, page 62), designed to assess emotional awareness within the 
context of a couple relationship and to assess the experiencing of hard and soft emotions in situations relevant to couples. This scale is structured similarly to the LEAS, with twelve brief interpersonal scenarios, but they involve the self and the partner. The scenarios portray a variety of common situations within a couple relationship, such as conflict between time spent at home and time with friends, or difficulties with increasing or decreasing intimacy. They were also designed to allow for expression of both hard and soft emotions. The exclusive use of partner scenarios augments the generic LEAS scenarios and may yield more in-depth information regarding emotional awareness within the couple relationship.

Based on the theoretical arguments described above, it is hypothesized that a relationship will be found between greater couple satisfaction and higher scores on the LEAS and CEAS. In addition, a discrepancy between partner scores may be critical for predicting dissatisfaction. Additionally, it will be interesting to see how emotional awareness within couples' relationships compares to emotional awareness in general, through scoring the CEAS according to LEAS criteria. It is hypothesized that higher CEAS scores will be more predictive of relationship satisfaction than higher LEAS scores because the CEAS scenarios are more focused on couples interactions.

\section{Method}

\section{Participants}

The participants in this study were 56 heterosexual couples who had been living together for at least one year. One same sex couple also participated. However, their data were not analyzed as they were the only same sex couple to volunteer and it was unclear how the 
dynamics of their relationship would affect the findings of this study. Participants had a median age of 25 years. They were generally highly educated, with $82 \%$ having attended some college or received a college diploma, and only $18 \%$ having a high school diploma or less. Most couples had no children $(65 \%)$ or one child $(14 \%)$, with only $21 \%$ having two or more children (see Table 3 for more complete demographic information, page 26). 19 of the couples were recruited from the community using advertisements and flyers and offered a financial incentive to participate. The remaining 37 couples had at least one member enrolled in a psychology class and participated to fill a class experimental requirement. All couples also participated in a concurrent study of couples' interactions, which is not expected to affect the findings of this study.

No significant risks to the participants were anticipated. To ameliorate any risk to the relationship as a result of negative insights and to respond to requests for counseling, a list of counselors in the community that practice couple counseling was available if requested. A graduate student trained according to a violence protocol and a suicide protocol was available to intervene at signs of domestic abuse or suicidal risk.

\section{$\underline{\text { Measures }}$}

Dyadic Adjustment Scale (DAS). The Dyadic Adjustment Scale (Spanier, 1976) is a selfreport measure of relationship satisfaction (see Appendix C, page 64). It has been used extensively in couple research and has good psychometric properties with Spanier (1976) reporting high internal consistency reliability with a Cronbach's alpha of .96 . Higher scores on the DAS reflect greater couple satisfaction. The average DAS score in this study was 
Table 3

Demographic Characteristics of Participating Couples

Variable

Age (years)

Race

Marital Status

Marital History

Time Living

Together (years)

Children

Joint Income

Education

Recruitment Source

\section{Characteristics of Participants}

$M d n=25, M=28.2$, Range from 19 to 68 (60\% from age 19 to 26 )

$92 \%$ white

$56 \%$ married to current partner $43 \%$ not married to current partner ( $1 \%$ did not respond)

$88 \%$ not previously married $11 \%$ previously married to another partner ( $1 \%$ did not respond)

$M d n=2, M=5.2$, Range from 1 to 35 (66\% from 1 to 3 years together)

$65 \%$ None

$14 \%$ One

$21 \%$ Two or more

$27 \%$ from $\$ 0$ to 10,000 per year $35 \%$ from $\$ 10,000$ to $\$ 20,000$ per year $34 \%$ above $\$ 20,000$ per year (4\% did not respond)

$18 \%$ high school diploma or less $53 \%$ some college $29 \%$ college diploma ( 2 year degree or above)

$66 \%$ recruited from a psychology class $34 \%$ recruited from the community 
$114.5(S D=13.87)$. This is similar to the expected average of 115 .

Levels of Emotional Awareness Scale (LEAS). The Levels of Emotional Awareness Scale (Lane, Quinlan, Schwartz, Walker, and Zeitlin, 1990; see Appendix A, page 59) is a 20 item structured interview measure of emotional awareness, based on a cognitivedevelopmental model of emotional awareness proposed by Lane and Schwartz (1987). The scale presents brief interpersonal situations and the participant is asked "How would you feel?" and "How would the other person (in the situation) feel?" The LEAS takes approximately twenty to thirty minutes to administer. Preliminary data on the LEAS indicate that it has good psychometric properties. Lane and colleagues (1990) reported high interrater reliability with Intraclass $r(20)=.84$, and high intratest homogeneity with a Cronbach's alpha of $.81(n=35)$.

Responses are each scored separately for self and for the other, from 0 to 4 . The lowest score, 0 , is for a nonemotion word where the word is presented as a feeling, such as "I would feel confused." This corresponds to the Sensorimotor Reflexive level of emotional awareness (refer to Table 2, page 21), where ability to describe emotions is either absent or limited to descriptions of bodily sensations. This mode of scoring progresses through each level, awarding progressively more points for greater identification and differentiation of feeling. For example, "sad but relieved" would receive more points than "sad" alone (Formal Operational with 4 points and Concrete Operational with 3 points respectively), because the combination of "sad" and "relieved" indicates greater emotional differentiation than either word alone. In turn, "sad" would receive more points than "bad" (Concrete 
Operational with 3 and Preoperational with 2 points respectively), because "bad" refers to a relatively undifferentiated feeling. These ratings are based entirely on structure of response, not on appropriateness.

Administration of the LEAS was audiotaped, and the participants' responses transcribed. The responses were scored by one of three raters who were blind to the DAS and CEAS scores of the couples. The scores were assigned according to the criteria outlined above and a scoring manual provided by the authors of the LEAS. Coders were trained by independently assigning codes to sample transcripts, then discussing any responses that had been rated differently by other coders in a group until consensus was reached. After training, reliability was checked between each rater and a criterion rater (Kristin Croyle), and exceeded an Intraclass $r$ of .60. At this point, coders began rating actual transcripts which were randomly assigned to coders, with coder 1 (male) scoring 36 transcripts, coder 2 (female) scoring 38 transcripts, and coder 3 (female) scoring 38 transcripts. Transcripts from the male and female of each couple were rated by the same coder. If a coder was uncertain how to score a particular response, the response was discussed by the coders as a group and a consensus was reached. Scores were prorated for participants with one or two nonscorable responses (responses inaudible on audiotape, etc.).

In this sample, the average score on the LEAS was 3.19 (ranging from 1.9 to 4.3 , $S D=44)$. Interrater reliability was calculated by comparing approximately twenty percent of the protocols scored by each rater to the same protocols scored by an independent rater. 
Interrater reliability on the LEAS was high, with and Intraclass $r(94)$ ranging from .80 to .92 for the three raters.

Couples' Emotional Awareness Scale (CEAS). The Couples' Emotional Awareness Scale (see Appendix B, page 62) is a 12 item structured interview measure of emotional awareness within couples' relationships developed for the current study. It is based partially on the structure of the LEAS, with brief interpersonal scenarios involving the self and the partner. After each scenario, the individual is asked "How would you feel?" and "How would your partner feel?", following the LEAS format. The CEAS takes approximately 10 to 20 minutes to administer. The CEAS was audiotaped, transcribed, and scored according to the same procedure described above for the LEAS. Each participant's CEAS and LEAS transcripts were scored by the same coder to avoid any variation in a participant's CEAS and LEAS scores due to differences between coders.

The CEAS was also scored according to the presence of hard and soft emotions, as defined by Jacobson and Christensen (1996), and the presence of positive emotions (such as happiness, humor, etc.), as these could not be categorized as hard or soft (see Appendix D, page 68 , for more detailed scoring instructions). Each response was examined for the presence of hard, soft, and positive emotions, and then given a score (yes or no) if these were present. For example, if a participant responded, "I would feel angry at first and probably a little hurt and scared. But then I would be glad that he was doing what he felt was right," the participant would receive scores for a hard emotion (anger), a soft emotion (hurt and scared grouped together), and a positive emotion (glad). Then these scores were summed 
across the 24 responses (twelve scenarios each with two prompts) yielding a total possible score for each participant of 24 hard emotions, 24 soft emotions, and 24 positive emotions.

Twelve participants were retested on the CEAS two to four weeks after their first administration. These retests were scored following the procedure described above for CEAS scoring by the same rater who scored their original responses. Raters were blind to the participants' original scores.

In this study, when the CEAS was scored according to LEAS criteria, the average score was 3.31 (ranging from 1.6 to $4.5, S D=.52$ ). When the CEAS was scored according to type of emotion (hard, soft, or positive), participants identified an average of 11.33 soft emotions (ranging from 2 to $21, S D=4.26$ ), 6.08 hard emotions (ranging from 0 to $16, S D=3.39$ ), and 4.18 positive emotions (ranging from 0 to $11, S D=2.55$ ). Additionally both men and women generally identified more hard emotions for themselves than for their partners $(t=$ $8.63, p<.001, n=112)$ and more soft emotions for their partners than for themselves $(t=$ $-5.01, p<.001, n=112$ ). This difference is probably due to the specific scenarios present on the CEAS, with several scenarios probably eliciting more hard emotions from the self and soft emotions from the partner.

Vocabulary section of the Wechsler Adult Intelligence Scale - Revised (WAIS-R). The Vocabulary subtest of the WAIS-R (Wechsler, 1981) was used as an estimate of verbal intelligence. It is a widely used measure with good psychometric properties. For the Vocabulary subtest, Wechsler (1980) reported a split-half reliability coefficient of .96 and a stability coefficient for individuals tested twice ranging from .91 to .93 . He also reported 
an intracorrelation between the Vocabulary subtest score and Verbal IQ score of .85. This subtest was used to determine if the LEAS and the CEAS may be highly influenced by verbal IQ or vocabulary rather than emotional awareness. It is possible that the vocabulary of participants influences their LEAS and CEAS scores because using more than one word to describe a feeling could elevate the scores. The subtest was administered and scored by trained research assistants.

\section{Procedure}

The couples were told that they were participating in a study of couples' emotions and communication. Following giving informed consent, each participant completed the DAS and a variety of other self-report measures, and was administered the LEAS, the CEAS, and the Vocabulary subtest of the WAIS-R. The order of LEAS and CEAS presentation was counterbalanced. All measures were administered in private rooms with only the participant and an experimenter present. Administration of the LEAS and CEAS was audiotaped, the participants' responses transcribed, and the responses scored by one of three raters who were blind to the other test scores of the couples. Following completion of the measures, the couple was debriefed, any residual negative feelings discussed with a graduate student in clinical psychology, a list of couple counselors provided if requested, and the compensation given.

Results

CEAS Reliability and Validity

The psychometric properties of the CEAS were analyzed by examining internal 
consistency, test-retest reliability, convergent validity and discriminant validity. Internal consistency, as measured by Cronbach's alpha, was good $(\alpha=.79, n=112)$ and was not increased by removing any items from the scale. To address test-retest reliability, 12 participants were retested after a two to four week interval. The correlation of their time one scores and time two scores was significant $(r=.70, p<.01)$, indicating that these scores are relatively stable over time. Addressing convergent and discriminant validity, LEAS and CEAS scores (as scored by LEAS criteria) were relatively highly and significantly correlated $(r=.59, p<.001, n=112)$. This indicates that the LEAS and CEAS are measuring similar areas, but that they are not completely overlapping.

Interrater reliability for the CEAS was calculated by comparing twenty percent of the protocols scored by each rater ( 8 protocols with approximately 12 responses each) to the same protocols scored by a criterion rater. When the CEAS was scored according to LEAS criteria, interrater reliability was high with intraclass $r(94)$ ranging from .80 to .87 for the three raters. When the CEAS was scored for type of emotion (hard, soft, or positive), interrater reliability was again high (Cohen's kappa ranging from .74 to .83 for the three raters).

\section{Relationship Between Emotional Awareness and Relationship Satisfaction}

The DAS, LEAS, CEAS (scored according to LEAS criteria), CEAS soft emotions total, CEAS hard emotions total, and CEAS positive emotions total were correlated to determine if they were related and, if so, in what direction. These correlations are reported in Table 4 (page 33). For women, several measures of emotional awareness (LEAS score, CEAS 
Table 4

Correlations of Emotional Awareness Scales and Dyadic Adjustment Scale $(n=112)$

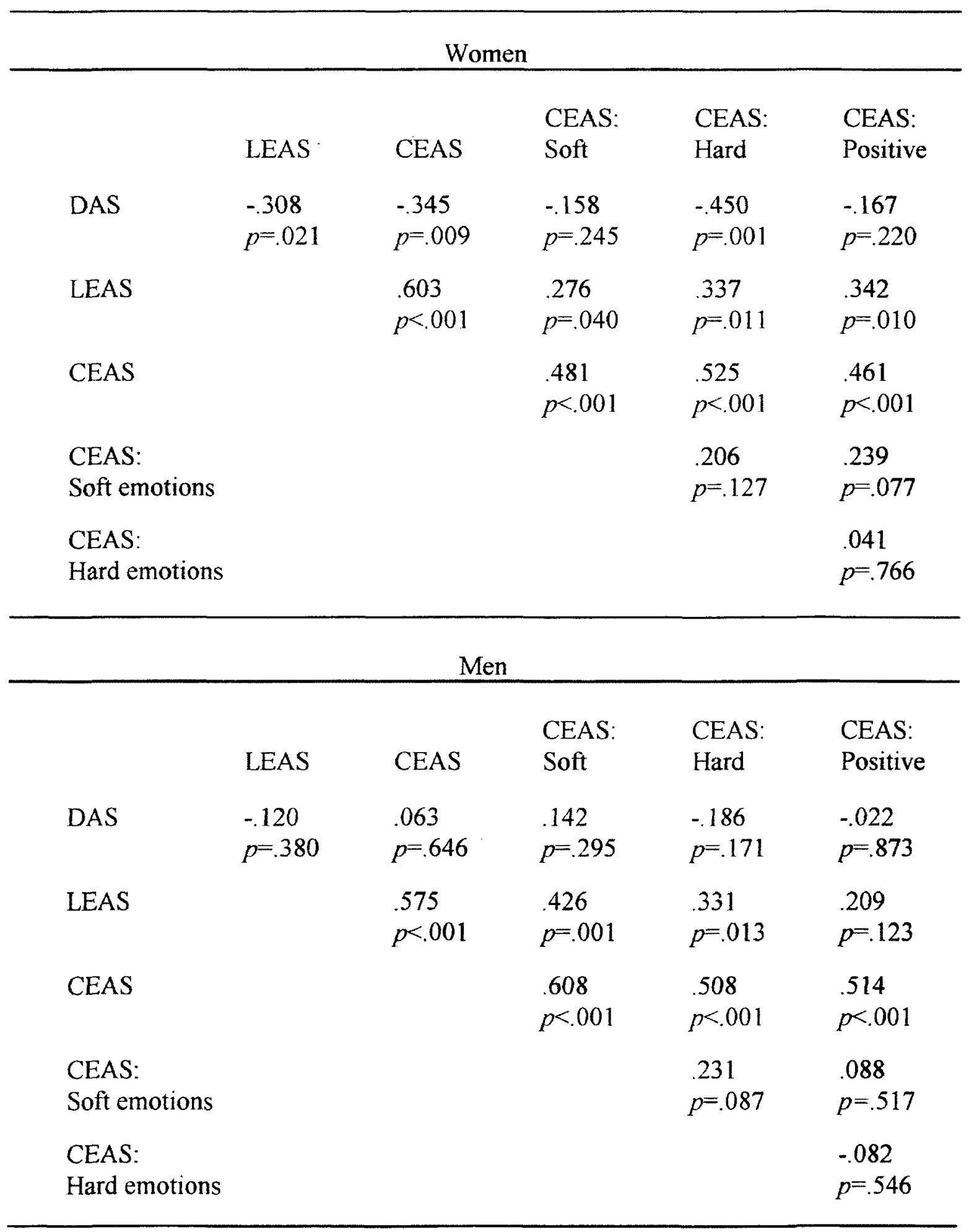


score, and CEAS hard emotions) were all significantly negatively correlated with DAS score. In other words, for women, higher levels of emotional awareness was related to lower relationship satisfaction. This is in the opposite direction as predicted. For men, none of the measures of emotional awareness were significantly related to DAS score. For both men and women, most of the other measures of emotional awareness were significantly intercorrelated, indicating that they are measuring similar areas. The only exception to this is awareness of hard emotions, soft emotions, and positive emotions. These appear to be relatively independent, as CEAS hard emotions, CEAS soft emotions, and CEAS positive emotions were not significantly related for men or women.

Predicting Relationship Satisfaction from Emotional Awareness

It was hypothesized that both an individual's own emotional awareness and their partner's emotional awareness would affect his/her relationship satisfaction. This hypothesis was tested by analyzing the predictability of relationship satisfaction from emotional awareness using two hierarchical regression analyses, one predicting relationship satisfaction from one's own emotional awareness variables and one predicting relationship satisfaction from partner emotional awareness variables. Vocabulary score was significantly correlated with both the LEAS $(r=.28, p=.003, n=111)$ and the CEAS $(r=.30, p=.001, n=111)$; therefore Vocabulary score was entered into the regression equations first to control for any effect that verbal skills may have. One male participant's data was not used in these regression analyses because he was not administered the Vocabulary subtest accurately and 
his resulting Vocabulary score was inaccurate, leaving 111 participants included in the regression analyses.

The first set of regressions predicted relationship satisfaction from personal emotional awareness variables including LEAS total score, CEAS total score (scored by LEAS criteria), CEAS total hard emotions, and CEAS discrepancy score (the absolute value of the difference between the partner's CEAS total score and personal CEAS total score). Men's and women's data were analyzed separately and the results are summarized in Table 5 (page 36). For women, their LEAS total scores, CEAS total hard emotions, and CEAS discrepancy scores were all significantly related to relationship satisfaction. For men, only their CEAS discrepancy scores appeared to be significantly related to relationship satisfaction. For women these emotional awareness variables together accounted for $40 \%$ of the total variance in relationship satisfaction while for men they only accounted for $18 \%$ of the variance.

The second set of regressions predicted relationship satisfaction from partner's emotional awareness variables including partner's LEAS total score, partner's CEAS total score (scored by LEAS criteria), partner's CEAS total hard emotions, and again the CEAS discrepancy score. This analysis was again used separately for men and women, with the results summarized in Table 6 (page 37). For women, only their CEAS discrepancy scores were significantly related to relationship satisfaction, while for men, none of the emotional awareness variables in these equations were significantly related to relationship satisfaction. For women, variables related to partner's level of emotional awareness accounted for $33 \%$ 
Table 5

Hierarchical Multiple Regression: Predicting Relationship Satisfaction from Personal Emotional Awareness Scores

\begin{tabular}{|c|c|c|c|c|c|}
\hline \multicolumn{6}{|c|}{ Women } \\
\hline$\underline{\text { Step }}$ & Variable & $\underline{B}$ & Beta & Multiple $R$ & $\underline{R^{2} \text { change }}$ \\
\hline 1 & Vocabulary & -.126 & -.090 & .090 & .008 \\
\hline 2 & LEAS & -.495 & $-.304^{*}$ & .308 & .087 \\
\hline 3 & CEAS & -.667 & -.252 & .367 & .040 \\
\hline 4 & CEAS (Hard only) & -1.928 & $-.379 *$ & .485 & .100 \\
\hline 5 & $\begin{array}{l}\text { CEAS discrepancy } \\
\text { (absolute value) }\end{array}$ & -1.286 & $-.426^{* * *}$ & .632 & .164 \\
\hline \multicolumn{6}{|c|}{ Men } \\
\hline Step & Variable & $\underline{B}$ & Beta & Multiple $R$ & $R^{2}$ change \\
\hline 1 & Vocabulary & .024 & .019 & .020 & .000 \\
\hline 2 & LEAS & -.228 & -.145 & .135 & .018 \\
\hline 3 & CEAS & .373 & .191 & .202 & .022 \\
\hline 4 & CEAS (Hard only) & -.951 & -.279 & .314 & .058 \\
\hline 5 & $\begin{array}{l}\text { CEAS discrepancy } \\
\text { (absolute value) }\end{array}$ & -.840 & $-.328^{*}$ & .420 & .079 \\
\hline
\end{tabular}


Table 6

Hierarchical Multiple Regression: Predicting Relationship Satisfaction from Partner Emotional Awareness Scores

\begin{tabular}{|c|c|c|c|c|c|}
\hline \multicolumn{6}{|c|}{ Women } \\
\hline Step & Variable & $\underline{B}$ & Beta & Multiple $R$ & $\underline{R^{2} \text { change }}$ \\
\hline 1 & Vocabulary & -.126 & -.090 & .090 & .008 \\
\hline 2 & Partner LEAS & .138 & .072 & .115 & .005 \\
\hline 3 & Partner CEAS & .377 & .159 & .172 & .016 \\
\hline 4 & Partner CEAS (Hard) & -1.200 & $-.290^{\mathrm{A}}$ & .289 & .054 \\
\hline 5 & $\begin{array}{l}\text { CEAS discrepancy } \\
\text { (absolute value) }\end{array}$ & -1.736 & $-.575 * * *$ & .570 & .242 \\
\hline \multicolumn{6}{|c|}{ Men } \\
\hline Step & Variable & $\underline{B}$ & Beta & Multiple $R$ & $\underline{R^{2} \text { change }}$ \\
\hline 1 & Vocabulary & .024 & .019 & .020 & .000 \\
\hline 2 & Partner LEAS & -.178 & -.134 & .135 & .018 \\
\hline 3 & Partner CEAS & -.422 & -.195 & .204 & .023 \\
\hline 4 & Partner CEAS (Hard) & -.186 & -.045 & .207 & .001 \\
\hline 5 & $\begin{array}{l}\text { CEAS discrepancy } \\
\text { (absolute value) }\end{array}$ & -.698 & $-.272^{\mathrm{B}}$ & .333 & .068 \\
\hline
\end{tabular}
A $p=.088$
B $p=.059$ 
of the total variance in relationship satisfaction while for men they only accounted for $11 \%$ of the variance.

\section{Relationship Between Discrepancy Scores and Relationship Satisfaction}

It was hypothesized that a larger difference between two partner's levels of emotional awareness would be related to a lower level of relationship satisfaction. To test this hypothesis CEAS and LEAS discrepancy scores (absolute value of personal emotional awareness total score minus partner's emotional awareness total score) were correlated with DAS scores (see Table 7, page 39). Results indicated that discrepancy in emotional awareness in response to couples situations is significantly negatively related to relationship satisfaction for both women and men. However, discrepancy in emotional awareness in response to general situations is not significantly related to relationship satisfaction for women or men.

To determine if the direction of the discrepancy had an effect on relationship satisfaction, these correlations were recalculated (see Table 7, page 39), with discrepancy calculated from partner's emotional awareness score minus personal emotional awareness score (not absolute value). For women, when emotional awareness was high relative to their partners, in response to both general situations and couples situations, they were less satisfied with their relationships. As their scores became closer to their partners', or dropped below their partners' scores, they became more satisfied. For men, the direction of the discrepancy was not important. 
Table 7

Correlations Between Discrepancy in Emotional Awareness and Relationship Satisfaction

General Discrepancy (absolute value of partner-self score)

\begin{tabular}{|c|c|c|}
\hline & $\begin{array}{c}\text { Women } \\
\text { DAS Score }\end{array}$ & $\begin{array}{c}\text { Men } \\
\text { DAS Score }\end{array}$ \\
\hline $\begin{array}{l}\text { LEAS } \\
\text { Discrepancy }\end{array}$ & $\begin{array}{c}-.232 \\
p=.085\end{array}$ & $\begin{array}{c}-.000 \\
p=.999\end{array}$ \\
\hline $\begin{array}{l}\text { CEAS } \\
\text { Discrepancy }\end{array}$ & $\begin{array}{c}-.501 \\
p<.001\end{array}$ & $\begin{array}{c}-.279 \\
p=.037\end{array}$ \\
\hline \multicolumn{3}{|c|}{ Directional Discrepancy (partner-self score) } \\
\hline & $\begin{array}{c}\text { Women } \\
\text { DAS Score }\end{array}$ & $\begin{array}{c}\text { Men } \\
\text { DAS Score }\end{array}$ \\
\hline LEAS & .333 & -.027 \\
\hline Discrepancy & $p=.012$ & $p=.847$ \\
\hline CEAS & .421 & -.228 \\
\hline Discrepancy & $p=.001$ & $p=.092$ \\
\hline
\end{tabular}




\section{Effect of Gender on Level of Emotional Awareness}

Scores were analyzed to determine if there was any difference between men and women in level of emotional awareness. In response to general situations (LEAS scores), there was no significant difference between men and women $(t=-1.41, p=.16, n$ pairs $=56)$. However, in response to couples situations (CEAS as scored by LEAS criteria), women scored significantly higher than men $(t=-2.65, p=.009, n$ pairs $=56)$.

\section{Discussion}

Based on the results discussed above, emotional awareness does appear to be important in couples relationships. Additionally, the CEAS appears to be a useful measure for assessing emotional awareness in response to couples' situations. Its use in this context, in conjunction with the LEAS, yields several results with interesting ramifications. These results and their implications in couples interactions are discussed below.

\section{Gender Differences in Emotional Awareness}

As described earlier, women appear to be more emotionally aware in response to salient couples situations than are men. That is, women report that they would experience more emotions, and more elaborated emotions, in response to salient couples situations than men report. In contrast, men and women do not differ in response to more general life situations. What could account for this difference between relationship situations and general situations for women? One possible explanation for this involves the unique characteristics of intimate couple relationships as opposed to gender differences independent of the specific relational context. There is evidence that women are socialized to be more aware of and focused on 
relationship dynamics and often feel responsible for the emotional health of their intimate relationships (Gilligan, Rogers, and Brown, 1990; Rampage, 1995). This focus on relationship dynamics may carry with it a higher level of emotional awareness, necessary to aid in monitoring the state of the relationship. It is possible that this higher level of emotional awareness is only brought into play in close relationships where the woman feels a responsibility to care for the health of the relationship. As men are generally not expected to be as attuned to the emotional aspects of their romantic relationships, they may not experience the same higher level of awareness within close relationships.

For example, the CEAS inquires about reactions to a situation in which the partner complains that the relationship is not as exciting as it once was. In response to this situation, a woman with a higher level of emotional awareness may be better able to monitor and maintain her relationship. A woman with a low level of emotional awareness may respond to this situation with one global term, saying something like, "I would feel bad." This would reflect a restricted range of emotion as well as a lack of differentiation of emotional experience. It would be difficult to use this information to help maintain the relationship. Should she respond to her partner with anger, with hurt, with fear, with inquiries about his emotional state? Consider an alternative response of a woman with a high level of emotional awareness. Her response could be something like, "I would feel hurt, of course. But I wouldn't be too surprised. Relationships are never as exciting later as they are when you're first dating (laugh). Mostly I'd be concerned about him and why he's bringing this up now. There must be something bothering him." This response indicates a broad range 
of emotions, clear differentiation of emotions, and an interest in describing a full emotional experience. This information would be much more helpful in attempting to maintain a relationship. This woman is aware of her emotions, able to use humor to modulate them, and attuned to her partner's possible emotional reactions.

These findings also indicate that women appear to have more elaborated ideas about how a couple situation would affect them and their partners than men do. There are two possible explanations for this. The first is that women may experience a broader range of emotions in response to relationship events than men. This would be a fundamental difference at the level of emotional experiencing, and any difference in emotional awareness would be explained by that. The second explanation is that men and women may experience similar emotions, but women may be more able to describe their emotional experiences. In other words, they may be more able to cognitively reflect on their emotional experiences, and thus have a higher level of emotional awareness. This would be a difference at the level of emotional awareness, but their fundamental emotional experiencing would be similar. These explanations have several implications.

If the first explanation were true, that women experience a broader range of emotions than men, it would seem likely that women would be more naturally able to empathize with others than men. If a woman was experiencing a broad range of emotions in response to a difficult situation, it would be likely that she would be experiencing at least an inkling of what the other person in the situation was experiencing. In contrast, if she was only experiencing a limited range of emotions; it would be less likely that she would be able to 
see beyond her dominant emotional experience. Similarly it may be more difficult for a man with a low level of emotional awareness ("I know I feel good about this.") to understand the response of a partner with a high level of emotional awareness ("I feel happy about it, but I'm also concerned, and a little anxious...") because he may view her responses as noncommittal, or overly emotional.

If the second explanation were true, that women are more able to describe their emotions, then it may be possible to bridge discrepancies between partners levels of emotional awareness by focusing on training the male partner to verbally express his emotions more clearly. If men and women are similar in their emotional experiencing, then it seems an easier task to focus on the communication of those emotions to each other than to attempt to tackle fundamentally different types of emotional experiencing. One couple that participated in this study is illustrative of this. In this couple, the woman was extremely adept at using emotion words to express herself and the man was noticeably not adept at this. The woman indicated that she was often annoyed that he could not use emotion words to label his experiences as quickly and adroitly as she could. It was her firm conviction that as he practiced talking about his emotions more (using a list of emotion words), his ability to talk about his emotions would gradually come to equal hers.

It is also certainly possible that both of these explanations are true and contribute to each other. Within romantic relationships, women may both experience a broader range of emotions and may be more able to reflect on their emotions and express them verbally. As their expertise at expressing their emotions verbally increases, they may then become even 
more aware of small distinctions between emotional experiences, in effect broadening their emotional experience.

Further research in this area could examine whether higher levels of awareness for women occur in all close relationships, including friendships, or only in particular relationships, such as romantic relationships. Additionally, this research could explore subtypes of relationship situations to determine if there are certain types of relationship situations that don't differ in the response of men and women. For example, does a woman experience a higher level of emotional awareness in close platonic relationships, or in family relationships? It could be that emotional awareness varies according to the degree of closeness of the relationship, or it could vary according to the quality of the relationship (e.g. romantic or non-romantic), or it could be unrelated to relationship characteristics. Additionally, do men and women differ in response to all couples situations, or couples situations regarding conflicting needs for intimacy but not regarding negotiating relationships with friends, for example? It is possible that certain conflict areas for couples may be critical in eliciting different responses for men and women, but other areas may not be important at all.

It would also be interesting to investigate the impact of a higher level of awareness on the relationship dynamics. Is a higher level of awareness related to a woman's tendency to take care of the relationship, as hypothesized above, or do they occur independently? What would be the impact on couple interactions in couples in which the male partner has a higher level of emotional awareness? If the above explanations are accurate and women do have 
a higher level of awareness so that they can better care for the emotional health of their relationships, it would seem that men with higher levels of awareness may be fulfilling a similar role. Do men in this situation take care of the emotional aspects of their relationships more than other men, or have they in a previous relationship where they learned to use a higher level of emotional awareness? Investigating each of these questions would certainly contribute to our understanding of couples relationships and the factors that influence their courses.

An alternative explanation of the above findings is that women may be more responsive to incidental qualities of the CEAS than men are. For example, participants were often more engaged in responding to the CEAS than to the LEAS because the scenarios were more complex, elicited more mixed emotional reactions, and often triggered more interest and reflection. Perhaps the engaging qualities of the CEAS were somehow influential to women's responses in a different way than to men's responses. It is possible that if women do indeed generally function at a higher level of emotional awareness than men, the more complex CEAS scenarios offered them a better opportunity to reflect and report on their emotions than the less subtle LEAS scenarios. Also, participants were given more opportunities to reflect on their emotions on the CEAS than on the LEAS. Perhaps this extra questioning was somehow influential to men and women differently.

The Association between Discrepancy in Partners Levels of Emotional Awareness and Relationship Satisfaction

Results indicate that discrepancy between partners' levels of emotional awareness in 
response to couples situations is related to decreased relationship satisfaction for both men and women. Further it appears that the direction of the discrepancy is not important for men. If the woman's awareness is higher than the man's awareness, this is equally related to decreased satisfaction as is the case if the man's awareness is higher than the woman's. However for women, the direction is important. If a woman's awareness is high, relative to her partner's, that is related to decreased satisfaction for her. However, as her partner's level of awareness increases, even if it exceeds hers, her relationship satisfaction is likely to increase also.

The initial findings that discrepancy is related to decreased satisfaction for both men and women are as predicted. One explanation for this is that it may be necessary for partners to have similar levels of emotional awareness to be able to easily communicate about emotion laden issues. If their levels of awareness are highly discrepant, their attempts to communicate their emotions to each other may not be understood. This is consistent with Mitchell's findings (1988) that distressed marriages often include partners who have difficulty communicating feelings, although one partner is often substantially more verbal than the other. This is also consistent with research findings that communication skills predict later relationship satisfaction (Holtzworth-Munroe \& Jacobson, 1991). Having similar levels of awareness may ease communication, as discrepant levels may be another barrier to overcome in striving for successful communication. People may also have the expectation that their partners should react to situations, express emotions, and talk about emotional issues in a similar way as themselves. This can be a powerful barrier to overcome 
in learning to communicate and empathize with your partner, as those expectations are rarely fully met.

In regard to the finding that the direction of the discrepancy is important for women but not for men, it is noteworthy that there were very few couples in which the man's level of awareness was substantially greater than the woman's level of awareness. In this sample, there were only 18 couples (of the total 56) in which the man's level of awareness was higher than the woman's in response to couples situations, and in 9 of these couples the man scored only one point higher than the woman (note the CEAS has an average total score of 39.7). In the remaining 9 couples, there was no clear pattern in the woman's relationship satisfaction. From these results, it seems clear that when a woman's level of emotional awareness exceeds her partner's, her relationship satisfaction is likely to be lower (as is his, as discussed above). However, since couples in which the man's level of awareness is substantially greater than the woman's level may have been underrepresented, it is unclear what the effect of this situation is on women's satisfaction.

\section{The Association between Emotional Awareness and Relationship Satisfaction}

Level of emotional awareness. This study found that higher levels of emotional awareness were related to decreased relationship satisfaction for women, and that higher levels of awareness actually predict decreased relationship satisfaction. This was true for emotional awareness in response to general situations, as well as in response to couples situations. These findings are in the opposite direction as predicted. For men, emotional awareness in itself did not appear to be important in predicting relationship satisfaction, 
except in cases where there was a difference in the level of awareness between the partners.

At face value these findings for women are contrary to what would be predicted by the existing literature. Greenberg and Johnson (1986) base their therapeutic approach on the assumption that increasing emotional awareness in couples can help them become more satisfied. Indeed they found that couples who had higher levels of emotional experiencing in therapy were more successful in therapy and ended therapy more satisfied than couples with lower levels of experiencing (Johnson \& Greenberg, 1988). However, findings from this study indicate that emotional awareness does not predict relationship satisfaction for men and is actually predictive of lower women's satisfaction. Almost every major psychotherapeutic approach attempts to increase client emotional awareness and experiencing, for a variety of justifications. Yet these findings indicate that, at least in one important area of life, a higher level of emotional awareness may not be helpful, at best. How can these discrepancies be explained?

First, it appears likely that the association between a higher level of awareness and decreased satisfaction for women may be partially, or even primarily, a function of a discrepancy between partners' levels of awareness. As noted above, discrepancies between partners' levels of awareness are related to decreased relationship satisfaction for both men and women. Also, women tend to have a higher level of awareness than men. It may be that it is not the higher level of awareness that necessarily contributes to lower satisfaction for women, but that with a higher level of awareness, a woman's level of awareness is more likely to be discrepant from her partner's level and it is this discrepancy which is related to 
lower satisfaction. Perhaps if the difference between the partners' levels of awareness could be minimized, then a higher level of awareness for women would not be related to decreased relationship satisfaction.

Second, these findings may still be consistent with psychotherapeutic approaches, including Greenberg and Johnson (1985), and Jacobson and Christensen (1996). Both of these approaches propose that increasing emotional awareness in a therapeutic context and using the higher level of awareness to restructure the relationship can increase relationship satisfaction. It may be that this second step, the application of the increased awareness to yield constructive change, is critical to the effect of increased awareness. In other words, insight into emotional experiencing would not be sufficient. Rather, lasting changes in behaviors must follow for relationship satisfaction to increase. Indeed, as these findings suggest, higher levels of emotional awareness may actually be detrimental for women if these behavioral changes do not follow. This is easily understandable. If a woman has a growing sense of dissatisfaction and anger within her relationship, this experience is likely to be quite painful if changes do not follow.

To clarify the associations between emotional awareness and relationship satisfaction, more research in this area is needed. Research that would be particularly useful would focus on level of emotional awareness, efforts to process and cope with difficult emotional issues, and their interaction with relationship satisfaction. It is possible that increased relationship satisfaction may be a combination of higher levels of emotional awareness and effective responses to those higher levels of awareness, including good communication skills and/or 
effective psychotherapy. Whether or not this interaction actually exists would be a useful next step in this sequence.

Hard and soft emotions. As hypothesized, this study found that awareness of more hard emotions was related to decreased relationship satisfaction for women. However, this relationship was not present for men. The findings for women are consistent with observations that unsatisfied couples often express a great deal of hard emotions and literature cited earlier that unsatisfied wives tend to show more negative affect than satisfied wives (Gottman \& Levenson, 1988). As this association only occurs for women and not for men, it would appear that women's relationship satisfaction is more closely associated with emotional factors. In other words, perhaps women experience relationship dissatisfaction in a more emotional way than men. For example, both partners in an unhappy relationship could experience dissatisfaction and unhappiness, but perhaps one partner could experience that dissatisfaction in a more emotional way (such as feeling extremely angry, disgusted, or irritated) while the other partner could experience it in a more cognitive way (such as being aware that certain needs are not being adequately met) or in a way that is more nonemotional (such as withdrawing from the relationship). Perhaps society's implicit permission for women to respond more emotionally than men allows women to experience more negative emotions associated with an unhappy relationship. Similarly, society's implicit punishment of men for reacting emotionally, and rewards for being "in control" and more action focused, directs men to respond to relationship distress in a less emotional fashion.

Interestingly, although it was hypothesized that soft emotions would also be associated 
with relationship satisfaction, this was not the case for either men or women. This is contrary to Jacobson and Christensen's prediction (1996) that if a couple can express soft feelings with each other, they will be able to communicate more effectively, experience more intimacy, and thus have a higher level of relationship satisfaction. What is responsible for this difference between hard and soft emotions for women, and for the apparent contradiction with Jacobson and Christensen's predictions?

One possible explanation is that soft emotions actually play little role in influencing relationship satisfaction, while hard emotions clearly do. It is quite possible that awareness and expression of hard emotions, such as anger, disgust, resentment, and irritation, are related to low relationship satisfaction for women. But that awareness and expression of soft emotions, such as hurt, sadness, sympathy, and caring, are relatively independent of relationship satisfaction for women. It may be that women are aware of these soft emotions in all relationships, and thus they do not vary with relationship satisfaction, while women may be more aware of hard emotions only within less satisfying relationships.

Another explanation is that awareness of soft emotions does vary between satisfied and unsatisfied relationships, but that this difference is not easily apparent. Soft emotions place the self in a vulnerable position in relation to the partner while hard emotions place the self in a more dominant position than the partner. Perhaps couples who are unhappy are reluctant to admit to or express soft emotions for fear of exposing a vulnerable side. Further, perhaps satisfied couples are also unlikely to express soft emotions, like hurt and sadness, because they simply do not experience them very often. 
This explanation clarifies the relationship between expression of soft emotions and relationship satisfaction. On one hand, Jacobson and Christensen (1996) proposed that greater awareness of soft emotions would encourage greater relationship satisfaction because they are more likely than hard emotions to elicit a sympathetic response. On the other hand, these findings show that even if soft emotions can encourage greater satisfaction in some cases, this does not appear to be generally true. One explanation for this is that it is very possible that expression of certain critical soft emotions in a therapy setting does encourage greater satisfaction, while expression of soft emotions in general in a nontherapeutic setting does not. It is also possible that by the time couples seek treatment for relationship distress, they may need help expressing and processing soft emotions, while couples in general do not need help in this area and thus for them soft emotions are not associated with satisfaction.

\section{Implications for Therapy and Research}

The clearest finding from this study is that emotional awareness is important in couples relationships and is particularly so for women, but not necessarily in the way predicted by existing research. Jacobson and Christensen (1996) and Greenberg and Johnson (1986) propose that higher levels of emotional awareness are important to relationship satisfaction and Jacobson and Christensen add that soft emotions may be particularly important. These findings indicate that a discrepancy between partners' levels of awareness, not general level of awareness, is particularly important in predicting low satisfaction, and that soft emotions are not critical. It should be noted that these discrepancy findings particularly apply to 
women who have a partner with a much lower level of awareness and to men who have a partner with a much different level (higher or lower) of awareness. It is unclear what would be the effect on women's satisfaction if their partner had a significantly higher level of emotional awareness.

This has several implications for both research and practice. In practice, it is important to note that focusing indiscriminately on developing emotional awareness may not be helpful for clients in and of itself. Rather, if a higher level of emotional awareness is a goal, then it must be followed with sensitive processing and consideration of a partner's level of awareness. Therapeutic approaches that focus on emotional awareness as a major piece generally are careful to use this focus on emotional awareness for a particular purpose. For example, Greenberg and Johnson (1986) and Jacobson and Christensen (1996) use the changes in emotional experiencing to restructure distressed couple relationships.

A second implication for practice uses the finding that discrepancies between partners' levels of emotional awareness are related to decreased relationship satisfaction. Perhaps focusing on acknowledging and accepting any discrepancy and developing techniques to minimize it, such as modifying communication patterns, would be helpful for dissatisfied couples. Conversely focusing on increasing the partner's level of awareness that is lower with the intention of decreasing the discrepancy between the partners may also be helpful for dissatisfied couples. Mitchell (1988) provides suggestions for working with clients to increase emotional awareness.

Research in this area also could continue on an exploratory path to clarify the association 
between higher levels of emotional awareness and decreased relationship satisfaction for women. Is this association due primarily to discrepancy between partners' levels of awareness, or is it present even if discrepancy is not? In this study, this association can be explained away by the discrepancy findings, but it would be helpful to follow-up on this research with a larger sample of women with a high level of emotional awareness with partner's who also had a high level of awareness, so that discrepancy would not be a possible contributing factor.

Emotional awareness, as it is demonstrated within the couple relationship, would also benefit from further research. This study is a first step in examining emotional awareness in relationships. However, emotional awareness, as operationalized here, may not be consistent with how emotional awareness plays out within the relationship. Even if they are consistent constructs, it is possible that emotional awareness as assessed is not always used within the relationship. For example, a man who shows a high level of emotional awareness when directly asked in a research setting may consistently interact with his partner at a lower level of awareness.

A replication of these findings would be helpful with a more diverse group of participants. For example, the participants in this sample were generally highly educated, young, white, and heterosexual. It is certainly likely that a more diverse sample would be different in many respects and may show different patterns of emotional awareness. It would be particularly interesting to follow up on these findings with a sample of same sex couples. Also, findings from this study are unclear concerning the relationship between 
satisfaction and partner discrepancy in level of awareness in heterosexual couples in which the man was significantly more aware than the woman. A larger sample, yielding more couples with discrepant levels of awareness would be helpful in investigating the effects of a discrepancy on relationship satisfaction. It would be interesting to compare the three possible discrepancy groups (no discrepancy, man's score higher, woman's score higher), with each group composed of a larger number of couples than were possible in this study.

As many researchers and therapists have proposed, emotional awareness does appear to be associated with relationship satisfaction for couples in a variety of ways. Women appear to be most strongly influenced by emotional awareness factors, although men are also affected by them. A particularly critical factor appears to be whether or not there is a discrepancy between partners' levels of emotional awareness. If a discrepancy exists, this is generally associated with lower levels of relationship satisfaction for both men and women. Research in this area is in early stages and is primarily exploratory, but as results from this study indicate, emotional awareness is indeed an important variable to take into account in both research and therapy. More in depth exploration would further understanding of couples relationships, the factors that influence their satisfaction, and eventually the therapeutic efforts that could be helpful to couples. 


\section{References}

Arnold, M. B. (1960). Emotion and personality: Volume I, psychological aspects. New York: Columbia University Press.

Blanck, G., \& Blanck, R. (1979). Ego psychology II: Psychoanalytic developmental psychology. New York: Columbia University Press.

Christensen, A., Jacobson, N. S., \& Babcock, J. C. (1995). Integrative behavioral couple therapy. In N. S. Jacobson \& A. S. Gurman (Eds.), Clinical handbook of couple therapy (pp. 31-64). New York: The Guilford Press.

Flavell, J. H. (1963). The developmental psychology of Jean Piaget. London: D. Van Nostrand Company, Ltd.

Gilligan, C., Rogers, A., \& Brown, L. M. (1990). Epilogue: Soundings into development. In C. Gilligan, N. P. Lyons, \& T. J. Hanmer (Eds.), Making connections: The relational worlds of adolescent girls at Emma Willard School (pp. 314-334). Cambridge, MA: Harvard University Press.

Gottman, J. M., \& Krokoff, L. J. (1989). Marital interaction and satisfaction: A longitudinal view. Journal of Consulting and Clinical Psychology, 57(1), 47-52.

Gottman, J. M., \& Levenson R. W. (1988). The social psychophysiology of marriage. In P. Noller \& M. A. Fitzpatrick (Eds.), Perspectives on marital interaction (pp. 182200). Cleveland, England: Multilingual Matters, Ltd.

Greenberg, L. S., \& Johnson, S. M. (1986). Affect in marital therapy. Journal of Marital and Family Therapy, 12(1), 1-10.

Greenberg, L. S., \& Johnson, S. M. (1988). Emotionally focused therapy for couples. New York: The Guilford Press.

Greenberg, L. S., \& Safran, J. D. (1987). Emotion in psychotherapy: Affect, cognition, and the process of change. New York: The Guilford Press.

Holtzworth-Munroe, A., \& Jacobson, N. A. (1991). Behavioral marital therapy. In A. S. Gurman \& D. P. Kniskern (Eds.), Handbook of family therapy (2nd ed., pp. 96-133). New York: Brunner/Mazel. 
Jacobson, N. S., \& Addis, M. E. (1993). Research on couples and couple therapy: What do we know? Where are we going? Journal of Consuiting and Clinical Psychology, 6l(1), 85-93.

Jacobson, N. S., \& Christensen, A. (1996). Integrative Couples Therapy: Promoting acceptance and change. New York: W. W. Norton \& Company, Inc.

James, P. S. (1991). Effects of a communication training component added to an emotionally focused couples therapy. Journal of Marital and Family Therapy, 17(3), 263-275.

Johnson, S. M., \& Greenberg, L. S. (1988). Relating process to outcome in marital therapy. Journal of Marital and Family Therapy, 14(2), 175-183.

Lane, R. D., Quinlan, D. M., Schwartz, G. E., Walker, P. A., \& Zeitlin, S. B. (1990). The levels of emotional awareness scale: A cognitive-developmental measure of emotion. Journal of Personality Assessment, 55 (1\&2), 124-134.

Lane, R. D., \& Schwartz, G. E. (1992). Level so emotional awareness: Implications for psychotherapeutic integration. Journal of Psychotherapy Integration, 2(1), 1-18.

Lazarus, R. S. (1982). Thoughts on the relations between emotion and cognition. American Psychologist, 37(9), 1019-1024.

Mandler, G. (1984). Mind and body: Psychology of emotion and stress. New York: W. W. Norton \& Company, Inc.

Mitchell, C. E. (1988). Teaching to speak in feelings as a second language. Family Therapy, $15(1), 75-81$.

Rampage, C. (1995). Gendered aspects of marital therapy. In N. S. Jacobson \& A. S. Gurman (Eds.), Clinical handbook of couple therapy (pp. 261-273). New York: The Guilford Press.

Raskin, N., \& Rogers, C. (1989). Person-centered therapy. In R. Corsini \& D. Wedding (Eds.), Current psychotherapies (pp. 155-194). Itaska, IL: Peacock.

Schachter, S., \& Singer, J. E. (1962). Cognitive, social, and physiological determinants of emotional state. Psychological Review, 69, 379-399.

Spanier, G. B. (1976). Measuring dyadic adjustment: New scales for assessing the quality of marriage and similar dyads. Journal of Marriage and the Family, 38, 15-28. 
Wechsler, D. (1981). Manual for the Wechsler Adult Intelligence Scale-Revised. New York: Psychological Corporation.

Werner, H. (1957). The concept of development from a comparative and organismic point of view. In D. B. Harris (Ed.), The concept of development: An issue in the study of human behavior (pp. 125-148). Minneapolis, MN: University of Minnesota Press. 
Appendix A

Levels of Emotional Awareness Scale (LEAS)

\section{Directions}

In this next part of the study I'm going to ask you some questions and audiotape your answers. Please describe what you would feel in the following situations. The only requirement is that you use the word "feel" in your answers. You may make your answers as brief or as long as necessary to express how you would feel. In each situation there is another person mentioned. Please indicate how you think that other person would feel as well. There are 20 situations. Any questions?

\section{$\underline{\text { Situations }}$}

1. A neighbor asks you to repair a piece of furniture. As the neighbor looks on, you begin hammering the nail but then miss the nail and hit your finger. How would you feel? How would the neighbor feel?

2. You are walking through the desert with a guide. You ran out of water hours ago. The nearest well is two miles away according to the guide's map. How would you feel? How would the guide feel?

3. A loved one gives you a back rub after you return from a hard day's work. How would you feel? How would your partner feel?

4. You are running in a race with a friend with whom you have trained for some time. As you near the finish line, you twist your ankle, fall to the ground, and are unable to continue. How would you feel? How would your friend feel?

5. You are traveling in a foreign country. An acquaintance makes derogatory remarks about your native country. How would you feel? How would your acquaintance feel?

6. As you drive over a suspension bridge you see a person standing on the other side of the guardrail, looking down at the water. How would you feel? How would the person feel?

7. Your sweetheart has been gone for several weeks but finally comes home. As your sweetheart opens the door....how would you feel? How would your sweetheart feel?

8. Your boss tells you that your work is unacceptable and needs to be improved. How would you feel? How would your boss feel? 
9. You are standing in line at the bank. The person in front of you steps up to the window and begins a very complicated transaction. How would you feel? How would the person in front of you feel?

10. You and your spouse (partner) are driving home from an evening out with friends. As you turn onto your block you see fire-trucks parked near your home. How would you feel? How would your spouse (partner) feel?

11. You have been working hard on a project for several months. Several days after submitting it, your boss stops by to tell you that your work was excellent. How would you feel? How would your boss feel?

12. You receive an unexpected long-distance phone call from a doctor informing you that your mother has died. How would you feel? How would the doctor feel?

13. You tell a friend who is feeling lonely that she/he can call you whenever she/he needs to talk. One night she/he calls at 4:00 a.m. How would you feel? How would your friend feel?

14. Your dentist has told you that you have several cavities and schedules you for a return visit. How would you feel? How would the dentist feel?

15. Someone who has been critical of you in the past pays you a compliment. How would you feel? How would the other person feel?

16. Your doctor told you to avoid fatty foods. A new colleague at work calls to say that she/he is going out for pizza and invites you to go along. How would you feel? How would your colleague feel?

17. You and a friend agree to invest money together to begin a new business venture. Several days later you call the friend back only to learn that she/he changed her/his mind. How would you feel? How would your friend feel?

18. You sell a favorite possession of your own in order to buy an expensive gift for your spouse (partner). When you give him/her the gift, he/she asks whether you sold the possession. How would you feel? How would your spouse (partner) feel?

19. You fall in love with someone who is both attractive and intelligent. Although this person is not well off financially, this doesn't matter to you -- your income is adequate. When you begin to discuss marriage (commitment), you learn that she/he is actually from an extremely wealthy family. She/he did not want that known for fear that people would 
only be interested in him/her for his/her money. How would you feel? How would she/he feel?

20. You and your best friend are in the same line of work. There is a prize given annually to the best performance of the year. The two of you work hard to win the prize. One night the winner is announced: your friend. How would you feel? How would your friend feel? 


\author{
Appendix B \\ Couples' Emotional Awareness Scale (CEAS)
}

\title{
Directions
}

In this next part of the study I'm going to ask you some questions and audiotape your answers. Please describe what you would feel in the following situations. The only requirement is that you use the word "feel" in your answers. You may make your answers as brief or as long as necessary to express how you would feel. I'll be giving you a second opportunity to check if you would be feeling any other feelings. In each situation your partner is mentioned. Please indicate how you think your partner would feel as well. There are 12 situations. Any questions?

\section{$\underline{\text { Situations }}$}

1. Your partner complains that you are spending too much time with your closest friend. How would you feel? Would you be feeling anything else? How would your partner feel?

2. Your aunt from out-of-town drops in unexpectedly. Neither you nor your partner get along with your aunt, and your partner frequently argues with her. Your partner decides to leave you and your aunt alone and go out with friends. How would you feel? Anything else? How would your partner feel?

3. Your partner agreed to pick you up from an evening activity but he/she is late and you have to wait outside. As you are standing outside waiting... How would you feel? Anything else? How would your partner feel?

4. In the past, when you have gone to parties with your partner and his/her coworkers, they have usually talked about things that you aren't interested in and you have been bored. Now there is a party coming up this weekend and your partner wants you to go. How would you feel? Anything else? How would your partner feel?

5. You have been working hard all week and you finally have a night off to unwind with your partner. But when you tell your partner, he/she tells you that he/she can't spend time with you that evening because he/she already has plans with his/her friends. How would you feel? Anything else? How would your partner feel?

6. You and your partner are struggling financially. Your partner is having troubles getting along with his/her boss. After being late to work one day, the boss fires him $/ \mathrm{her}$. How would you feel? Anything else? How would your partner feel? 
7. You've had a long, exhausting day and you tell your partner that you need some time alone to unwind. Your partner says he/she would really like to talk to you about his/her day. How would you feel? Anything else? How would your partner feel?

8. One night, as you and your partner are going to bed, a friend of your partmer's calls and says that he/she (use sex of subject) needs your partner right away for emotional support about a personal crisis. Your partner leaves to visit his/her friend. How would you feel? Anything else? How would your partner feel?

9. One afternoon, your partner comes home from work and you are on the phone with a male/female (use sex of partner) friend. Later your partner tells you that he/she is upset and worried that you are attracted to your friend. How would you feel? Anything else? How would your partner feel?

10. Your partner comments that your relationship is not as exciting as it was when you first met. How would you feel? Anything else? How would your partner feel?

11. One evening, you have several important things you need to work on, but your partner keeps interrupting you. He/she explains that he/she wants to spend extra time with you this evening. How would you feel? Anything else? How would your partner feel?

12. Your partner's boss asks him/her to go to Hawaii to take care of some business, all expenses paid. However, the company won't pay for you to go as well, so your partner decides to go alone. How would you feel? Anything else? How would your partner feel? 
Appendix C

Dyadic Adjustment Scale (DAS)

Most people have disagreements in their relationships. Pleage indicate below the approximate extent of agreement. or disagreement between you and your partner for each Item on the following list.

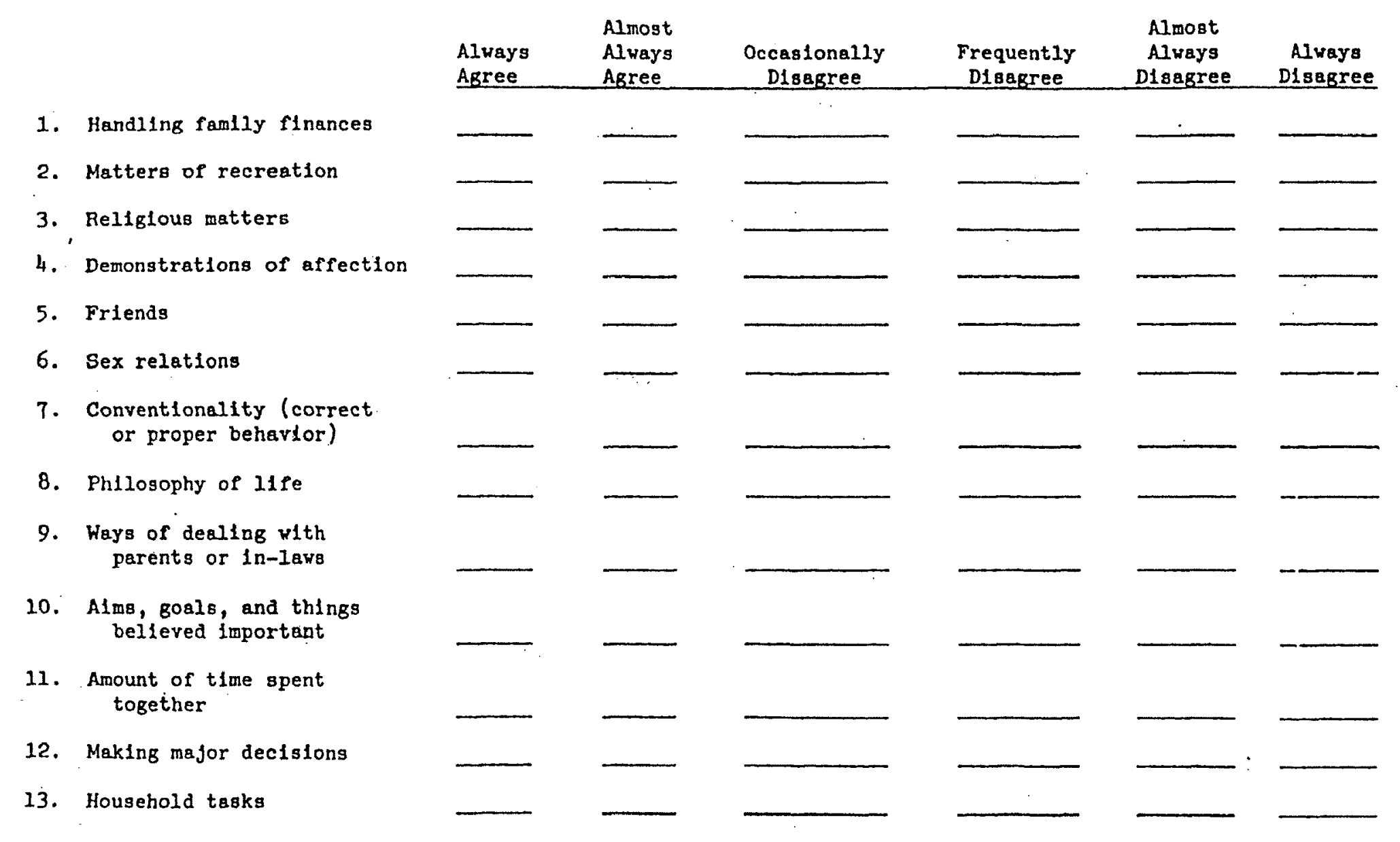


14. Lelsure time interests and activities

15. Career declsions

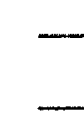

\section{All}

the time

16. How often do you discuss or have you consldered divorce, separation or terminating your relationshtp?

17. How often do you or your mate leave the house after a flght?

18. In genersl, hov often do you think that things between you and your partner are golng vell?

19. Do you conflde in your mate?

20. Do you ever regret that you marrled (or live together)?

21. How often do you and your partner quarrel?

22. How often do you and your mate get on each others' nerves?
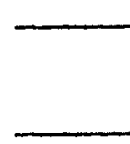$$
+
$$
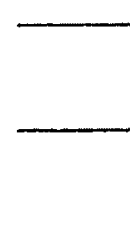

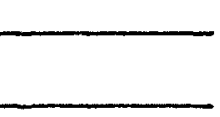

More often

than not

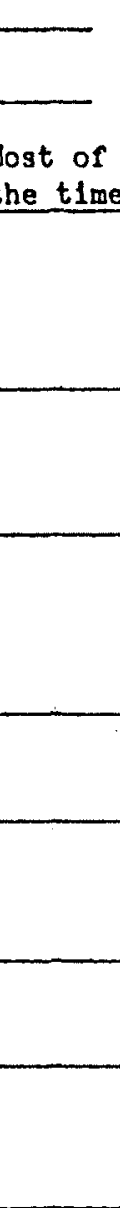

Occasionally

Rarely

Never 
Every day Almost every day Occasionally Harely Never

23. Do you kiss your mate?

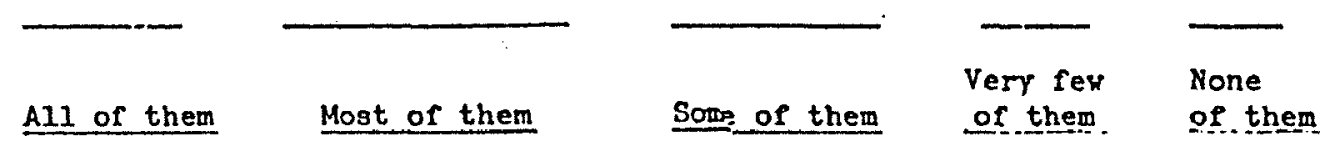

24. Do you and your mate engage in outside interests together?

How often would you say the following events occur between you and your mate?

$\begin{array}{llcc}\text { Less than } & \text { Once/twice } & \text { Once/twice once More } \\ \text { Never } & \text { once a month } & \text { a month } & \text { aveek }\end{array}$

25. Have a stimulating exchange of 1 dess

26. Laugh together

27. Calmiy discuss something

28. Work together on a project

These are things about which couples sometimes agree and sometimes disagree; Indicate'1f either"1tem below caused differences of oplnions or were problems in your relationship during the past few. weeks. (Check yes or no)

$$
\text { Yes No }
$$

29. Belng too tired for sex

30. Not showing love

31. The dots on the following line represent different degrees of happlness in your relationshlp. The middle point. "heppy", represents the degree of happlness of most relationships. Please clrcle the dot which best describes the degree of heppiness, all things consldered, of your relationship.

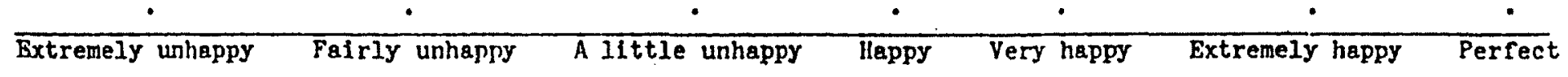


32. Which of the following statements best describes how you feel about the future of your relstionshlp? I want desperately for my relationship to succeed, and yould go to about any length to see that It does.

I want very much for my relationshlp to succeed, and w111 do all I can to see that it does.

I want very much for my relationship to succeed, and will do my fair share to see that 1t does. It would be nice if my relationshlp succeeded, but I can't do much more than I am do!ng now to help it succeed.

It would be nice if my relationshlp succeeded, but I refuse to do any more than I am colng nor to keep the relationship golng.

My relationship can never succed, and there 1s no more that I can do to keep the relationship golng. 


\section{Appendix D \\ Couples' Emotional Awareness Scale \\ Scoring Instructions for Hard and Soft Emotions}

When scoring for hard and soft emotions, CEAS responses should be scored according to overall intent of the respondent, rather than focusing on categorizing each separate emotion word. The examples given below are only rough guidelines and could be categorized differently if the context seems to indicate. Code for the presence of each type of emotion rather than counting the number of emotion words used, i.e. check off each type of emotion that is present.

Hard Emotions Definition: Hard emotions tend to put the self in a stronger, more dominant position relative to the partner.

$\begin{array}{llll}\text { Examples: } & \text { aggravated } & \text { dissatisfied } & \text { jealous } \\ \text { angry } & \text { frustrated } & \text { offended } \\ \text { annoyed } & \text { inconvenienced } & \text { resentful } \\ \text { defensive } & \text { irritated } & \text { he really screwed up }\end{array}$

Soft Emotions Definition: Soft emotions tend to reveal the self as vulnerable relative to the partner.

\begin{tabular}{|c|c|c|c|}
\hline Examples: & $\begin{array}{l}\text { abandoned } \\
\text { afraid } \\
\text { alarmed } \\
\text { awkward } \\
\text { bad }\end{array}$ & $\begin{array}{l}\text { concerned } \\
\text { considerate } \\
\text { disappointed } \\
\text { embarrassed } \\
\text { guilty }\end{array}$ & $\begin{array}{l}\text { pressured } \\
\text { sad } \\
\text { sympathy } \\
\text { threatened } \\
\text { worried }\end{array}$ \\
\hline
\end{tabular}

Positive Emotions Definition: Positive emotions are generally happy. These do not include emotions that are socially positive, but not generally happy, such as sympathy.

$\begin{array}{llll}\text { Examples: } & \text { good } & \text { like } & \text { relieved } \\ \text { grateful } & \text { loving } & \text { touched } \\ \text { happy } & \text { nice } & \\ \text { hopeful } & \text { proud } & \end{array}$

Sometimes responses will not include hard, soft, or positive emotions, or will be too general to categorize.

$\begin{aligned} & \text { Examples: } \text { bored } \\ & \text { busy } \\ & \text { confused } \\ & \text { curious }\end{aligned}$ fine surprised OK upset curious shocked

When scoring responses for "How would your partner feel?" score the response as though the respondent is speaking in first person. In other words, if the response is "I think that my partner would feel sad," score that as a soft emotion for the partner. 